\title{
TRABALHO E TECNOLOGIA BANCÁRIA: DINÂMICAS E CONTRADIÇÕES DO BRASIL DO SÉCULO XXI.
}

\author{
WORK AND BANKING TECHNOLOGY: \\ DYNAMICS AND CONTRADICTIONS OF BRAZIL OF THE 2IST CENTURY. \\ TRAVAIL Y TECHNOLOGIE BANCAIRE: \\ DYNAMIQUES ET CONTRADICTIONS DU BRÉSIL AU 2IĖME SIËCLE.
}

TRABAJO Y TECNOLOGÍA BANCARIA: DINÁMICAS Y CONTRADICCIONES DE BRASIL EN EL SIGLO XXI.

Luiza Borges Dulci*

RESUMO: A tecnologia é chave para a compreensão da história e do trabalho nos bancos. As inovações eletrônicas, sobretudo após a internet, alteraram sobremaneira a rotina de trabalho nos bancos, as relações de poder, a interação com os clientes e as formas de controle do processo de trabalho. As evidências mostram que os efeitos do emprego sobre o trabalho devem considerar o contexto socioeconômico. A análise do emprego e das condições e relações de trabalho nos bancos do Brasil do século XXI seguiram duas tendências distintas. No período de expansão econômica com distribuição de renda, houve aumento do emprego, diversificação das formas de contratação, com crescimento expressivo dos terceirizados, e ampliação das conquistas sindicais. As novas tecnologias diversificaram os canais de interação entre bancos e clientes com vistas a ampliação da venda de produtos e serviços financeiros. Exige-se dos trabalhadores o perfil de vendedores e consultores de negócios, ao mesmo tempo em que crescem as pressões por metas e cobranças oriundas dos bancos e dos clientes. A reversão do cenário macroeconômico favorável interrompeu o período de conquistas de direitos e produziu desemprego. Todas essas alterações trazem desafios para cada trabalhador, para as representações sindicais e para a própria teoria social.

Palavras chave: Tecnologia; Trabalho; Bancos; Sistema financeiro; Relações de trabalho.

\footnotetext{
* Mestre em Sociologia e Antropologia (PPGSA-UFRJ) e doutoranda no Programa de Pós-Graduação de Ciências Sociais em Desenvolvimento, Agricultura e Sociedade da Universidade Federal Rural do Rio de Janeiro (CPDA-UFRRJ), Rio de Janeiro, RJ, Brasil; E-mail: luiza.dulci@gmail.com
} 
ABSTRACT: Technology is key to understanding history and working in banks. Electronic innovations, especially after the Internet, have greatly altered the work routine in banks, power relations, interaction with customers and ways of controlling the work process. Evidence shows that the effects of employment on labor should consider the socioeconomic context. The analysis of employment and working conditions and relations in Brazilian banks of the 21st century followed two different trends. In the period of economic expansion with income distribution, there was an increase in employment, a diversification of hiring methods, a significant increase in outsourcing, and an increase in union achievements. The new technologies diversified the channels of interaction between banks and clients with a view to increasing the sale of financial products and services. Workers are required to be profile salespeople and business consultants, at the same time as the pressure for targets and collections from banks and customers grows. The reversal of the favorable macroeconomic scenario interrupted the period of gains of rights and produced unemployment. All these changes bring challenges for each worker, for trade union representations and for social theory itself.

Keywords: Technology; Work; Banks; Financial system; Labour relations.

RÉSUMÉ: La technologie est la clé pour comprendre l'histoire et le travail dans les banques. Les innovations électroniques, en particulier après Internet, ont considérablement modifié la routine de travail dans les banques, les relations de pouvoir, l'interaction avec les clients et les moyens de contrôler le processus de travail. Les faits montrent que les effets de l'emploi sur le travail devraient tenir compte du contexte socioéconomique. L'analyse des conditions d'emploi et de travail et des relations dans les banques brésiliennes au 2lème siècle a suivi deux tendances différentes. Dans la période d'expansion économique et la répartition des revenus, une augmentation de l'emploi, la diversification des formes d'emploi, avec une forte croissance de l'externalisation et l'expansion des réalisations syndicales. Les nouvelles technologies ont diversifié les canaux d'interaction entre banques et clients en vue d'accroître la vente de produits et services financiers. Les travailleurs doivent avoir le profil des vendeurs et des consultants en affaires, en même temps que la pression pour les objectifs et les collections des banques et des clients augmente. L'inversion du scénario macroéconomique favorable a interrompu la période de gains des droits et a produit du chômage. Tous ces changements créent des défis pour chaque travailleur, pour les représentations syndicales et pour la théorie sociale elle-même.

Mots clés: Technologie; Travail; Banques; Système financier; Relations de travail. 
RESUMEN: La tecnología es clave para la comprensión de la historia y el trabajo en los bancos. Las innovaciones electrónicas, sobre todo después de Internet, han cambiado mucho la rutina de trabajo en los bancos, las relaciones de poder, la interacción con los clientes y las formas de control del proceso de trabajo. Las evidencias muestran que los efectos del empleo sobre el trabajo deben considerar el contexto socioeconómico. El análisis del empleo y de las condiciones y relaciones de trabajo en los bancos de Brasil del siglo XXI siguieron dos tendencias distintas. En el periodo de expansión económica con distribución de renta, hubo aumento del empleo, diversificación de las formas de contratación, con crecimiento expresivo de los tercerizados, y ampliación de las conquistas sindicales. Las nuevas tecnologías han diversificado los canales de interacción entre bancos y clientes con mira a la ampliación de la venta de productos y servicios financieros. Se requiere de los trabajadores el perfil de vendedores y consultores de negocios, al mismo tiempo que crecen las presiones por metas y cobros provenientes de los bancos y de los clientes. La reversión del escenario macroeconómico favorable interrumpió el período de conquistas de derechos y produjo desempleo. Todos estos cambios traen desafíos para cada trabajador, para las representaciones sindicales y para la propia teoría social.

Palabras clave: Tecnología; Trabajo; Bancos; Sistema financiero; Relaciones laborales.

\section{INTRODUÇÃO}

A realidade da automação nos bancos é mundial e está em constante transformação. As tecnologias bancárias acarretam mudanças que impactam a natureza das tarefas executadas; o tipo e o grau de qualificação exigidos dos trabalhadores; seu perfil social, econômico e político; as relações de poder constituídas no interior das instituições financeiras e os modos de produzir. Tais mudanças têm postos novos e diferentes desafios para cada trabalhador, para as representações sindicais e para a própria teoria social.

O presente estudo analisa as transformações nos bancos brasileiros e no trabalho bancário decorrentes da introdução das novas tecnologias nas duas primeiras décadas do século XXI. Desenvolvidas com os propósitos de ampliar a rede de clientes e reduzir custos, sendo o principal deles a mão de obra, as tecnologias, em particular, as tecnologias digitais, têm levado a uma reconfiguração no mercado de trabalho bancário. 
Em 2017 o setor bancário se igualou ao setor público e ambos foram os maiores investidores em tecnologia no país, cada um com participação de $15 \%$ do Produto Interno Bruto'. Os R \$ 19,5 bilhões investidos pelos bancos foram destinados ao desenvolvimento e aprimoramento de softwares e máquinas (hardwares), com ênfase na segurança das transações e na customização dos serviços disponíveis aos usuários das plataformas digitais (Febraban, 2018).

Outro aspecto importante tem a ver com a realização de parte das atividades bancárias em locais externos às agências e demais unidades administrativas dos bancos. As operações bancárias têm sido cada vez mais direcionadas para estruturas físicas alternativas e para as plataformas digitais, acessíveis pelo computador e pelo celular. Dentre os espaços físicos alternativos há os correspondentes bancários, cujas operações são desempenhadas por trabalhadores não bancários, ou seja, terceirizados - as casas lotéricas são o exemplo mais conhecido. Outro meio de externalização das atividades são os Contact Center, ou call centers, que concentram os atendimentos telefônicos dos bancos.

A terceirização é, de fato, um dos fenômenos que mais transformou o mercado de trabalho bancário dos anos 1990 para cá. Inicialmente restrita às áreas de limpeza e de segurança das agências, esta modalidade de contratação abarca atualmente até mesmo as áreas comercial e de negócios dos bancos. A ampliação quali e quantitativa das atividades terceirizadas deve-se a três fatores principais. O primeiro deles é a busca pela redução de custos, especialmente após a redução dos sobrelucros que marcaram o período inflacionário. $\mathrm{O}$ segundo tem a ver com as medidas de regulação estatal e legislações, que vieram flexibilizando as formas de contratação e subcontratação e ampliando o rol de atividades terceirizáveis. Por fim, o terceiro fator, diz respeito às inovações tecnológicas, que possibilitam o distanciamento e a externalização de parte da atividade bancária. As plataformas digitais se apresentam como outra forma de externalização dos serviços com vistas à redução dos custos. Nesse caso, os próprios clientes conduzem as operações bancárias, sem necessitar do acompanhamento imediato de funcionários.

1 Para comparação internacional, em 2015 a média de investimentos em tecnologia bancária no mundo foi de $13 \%$, enquanto os investimentos em tecnologia pelo setor público eram de $16 \%$ (Febraban, 2018). 
Implementadas com o mesmo objetivo de reduzir custos, estas duas estratégias - terceirização e ampliação dos canais digitais - orientam-se a públicos distintos. Isto é, propiciam a segmentação dos clientes dos bancos. Os correspondentes bancários voltam-se, prioritariamente, a públicos de baixa renda e aos usuários e clientes localizados em municípios desprovidos de agências bancárias. As tecnologias digitais, por sua vez, têm como público alvo prioritário os clientes das classes média e alta, com maior escolarização e fácil acesso à internet. Ao passo que os clientes mais pobres são direcionados para fora das agências, os clientes do topo da pirâmide são recebidos em espaços exclusivos, caso das agências Estilo (Banco do Brasil), Personalité (Itaú) e Select (Santander), onde o atendimento e os serviços são personalizados.

Dentre as várias transformações decorrentes das inovações tecnológicas, nos interessa analisar aqui àquelas relativas ao trabalho. No que diz respeito à dimensão do contingente bancário brasileiro, ressalta-se que a categoria reduziu pela metade desde meados dos anos 1980 aos dias de hoje, passando de um contingente de cerca de um milhão de trabalhadores em 1985 para aproximadamente 504 mil em 2015. Contudo, na última década o conjunto dos trabalhadores do ramo financeiro - que inclui bancários; securitários; trabalhadores de empresas de crédito cooperativo, agências de fomento; gestão de ativos; dentre outros ${ }^{2}$ - retomou o patamar de emprego de meados dos anos 1980, chegando a contabilizar mais de 1 milhão de trabalhadores entre 2011 e 2014. Este aumento se deu no contexto de crescimento econômico do país e de aumento da chamada bancarização das parcelas da população que se viam às margens do sistema financeiro. Com o fim do período de crescimento, os números da expansão bancária e do aumento do emprego foram interrompidos e já apresentam tendência de declínio.

Os processos de controle do trabalho constituem outra dimensão chave das transformações em curso. Assim, tão importante quanto evidenciar os efeitos da tecnologia sobre os níveis de emprego, é considerar o processo de reconfiguração das formas de inserção no mercado de trabalho bancário, bem como as variadas

2 Para a lista completa das categorias pertencentes ao ramo financeiro ver Contraf-Cut, 2017, p. 12. 
condições e relações de trabalho no ramo financeiro de maneira geral. Cabe perguntar, portanto, como as tecnologias vem alterando a rotina de trabalho nos bancos? Quais as estratégias dos bancos para o controle do trabalho? E quais os impactos sobre as relações entre bancos, bancários e clientes?

Para responder a estas perguntas e levar a cabo os objetivos propostos, este artigo está estruturado em três seções, além desta Introdução. A seção dois analisa as principais transformações vivenciadas pelo sistema bancário brasileiro, desde a década de 1960, com ênfase nas mudanças tecnológicas introduzidas a partir da chegada da internet em meados dos anos 1990. A terceira seção se volta aos efeitos das mudanças tecnológicas sobre as relações de trabalho nos bancos e sobre o mercado de trabalho bancário e no ramo financeiro como um todo. Em seguida, na quarta e última seção, são apresentadas algumas notas conclusivas.

\section{A AUTOMAÇÃO NOS BANCOS BRASILEIROS}

Há duas sortes de questões que devem ser consideradas quando tratamos da estruturação e da modernização do sistema bancário brasileiro a partir de meados do século XX. Ambas tiveram início nos anos 1960 e atuaram de forma complementar, abrindo caminho para o processo de modernização dos bancos. A primeira delas consiste na Reforma Bancária e a segunda diz respeito às tecnologias introduzidas nos bancos. A Reforma Bancária (Lei n. 4.595/1964) foi, desde fins dos anos 1940, longamente debatida no Congresso Nacional e, quando aprovada, veio a consolidar o sistema bancário brasileiro em âmbito efetivamente nacional. Ela criou o Banco Central do Brasil e o Conselho Monetário Nacional (CMN), estabeleceu a regulamentação sobre a participação de bancos estrangeiros no país e sobre a relação dos bancos com as empresas dos demais setores da economia, dentre outras medidas (Minella, 1988).

Para consolidar-se de vez, a expansão do sistema financeiro nacional exigia ainda mecanismos de controle das operações e das rotinas bancárias, que deviam ser padronizadas em todo o país. Des- 
sa forma, os processos administrativos passaram a ser mais centralizados, ao passo que os serviços prestados seguiam o caminho da descentralização. A homogeneização dos procedimentos contábeis, conhecida como Padronização Contábil dos Estabelecimentos Bancários (PACEB), promovida pelo Banco Central em 1967, foi idealizada justamente para normatizar o controle e a fiscalização dos movimentos diários dos bancos. Somente a partir daí foi possível a expansão descentralizada do sistema financeiro nacional. Além disso, nos anos 1960 e 1970, bancos estrangeiros adentraram o sistema financeiro brasileiro, ao mesmo tempo em que houve um movimento de concentração financeira, ou seja, de oligopolização.

As alterações ocorridas na regulamentação do sistema financeiro nos anos 1980 foram escassas. Contudo, duas delas alteraram sobremaneira sua organização, até então segmentada: a extinção das cartas-patentes, que impunham a obrigação de autorização para a entrada de instituições no sistema financeiro; e a autorização do CMN para a criação dos bancos múltiplos. A Constituição Federal de 1988 trata do Sistema Financeiro Nacional em seu art. 192, contudo, este nunca foi regulamentado (Ianoni, 2010).

Nos anos 1990 o sistema financeiro brasileiro passou por um período de reestruturação, alinhado com as orientações de abertura da economia brasileira sob os preceitos do Consenso de Washington. Tal processo foi marcado pela ampliação de bancos estrangeiros no país e pela multiplicação das fusões e aquisições, que intensificaram ainda mais a concentração bancária (Araújo, Cartoni e Justo, 2001; Camargo, 2009).

O controle inflacionário decorrente do Plano Real provocou queda na rentabilidade dos bancos e aumento da competição interbancária, ao passo que a crescente suscetibilidade às crises internacionais, decorrentes da abertura econômica, provocaram perdas em inúmeros bancos, tendo vários deles ido à falência. Na tentativa de contrabalançar a queda na rentabilidade, aproveitando dos altos juros e spreads bancários, os bancos aumentaram a oferta de crédito e focaram grande parte de seus recursos no financiamento da dívida pública nacional. Além disso, impulsionaram a busca pela racionalização dos processos; passaram a investir na venda de produtos e serviços financeiros; 
e foram alvo de políticas governamentais de "saneamento" do sistema financeiro brasileiro. As principais mudanças incluem a adesão ao Acordo da Basiléia, em 1994; a autorização para a cobrança de tarifas bancárias, em 1996; e os incentivos às fusões e aquisições - com políticas de privatização como o Programa de Incentivo à Redução do Setor Público Estadual na Atividade Bancária (Proes) e o Programa de Estímulo à Reestruturação e ao Fortalecimento do Sistema Financeiro Nacional (Proer). Os anos 2000 e 2010, por sua vez, tiveram como um dos traços mais significativos o processo conhecido como bancarização ${ }^{3}$, caracterizado pela expansão da rede de usuários (contas bancárias, operações transacionadas e volume de crédito) e de agências e postos de atendimento bancário no país.

$\mathrm{O}$ interesse deste artigo diz respeito, sobretudo, à segunda questão que influenciou a modernização bancária brasileira: as mudanças tecnológicas. A inovação que deu início às grandes transformações na atividade bancária coube aos chamados Centros de Processamento de Dados (CPDs), que chegaram aos bancos na década de 1960. Os CPDs caracterizaram o início da fragmentação e da racionalização do trabalho nos bancos, na medida em que as informações passaram a ser apreendidas - colecionadas, classificadas, combinadas e tabuladas - pelas próprias máquinas.

Em meados dos anos 1970, a automação alcançou os terminais de trabalho dos caixas, e, com isso, tornou-se visível aos clientes das agências. A conexão online entre os terminais e os sistemas de processamento acelerou a transmissão de dados, que tornou-se mais segura. O que diferenciou a tecnologia da década de 1970 com aquela da década anterior foi o desenvolvimento dos sistemas operacionais propriamente ditos. Antes, o que havia eram terminais monoprogramáveis, que realizavam somente uma tarefa por vez.

Foi também neste período que vigorou no Brasil a política de reserva de mercado na área de sistemas e de processamento de dados. Tal política veio a ser implantada em 1974, após o primeiro choque do petróleo, a partir do diagnóstico de que os dispêndios em equipamentos eletrônicos

$3 \mathrm{O}$ indicador de bancarização é calculado pela razão entre o número de Cadastros de Pessoas Físicas (CPFs) únicos ativos no Banco Central do Brasil com 15 anos ou mais e o total da população desta mesma faixa etária. 
pesavam demasiada e negativamente no Balanço de Pagamentos do país. Diante disso, o governo passou a controlar a importação de máquinas e equipamentos de menor porte, tornando imperativo o desenvolvimento nacional de tais tecnologias (Fonseca, Meirelles e Diniz, 2010).

Até o início dos anos 1980 a automação bancária consistiu na difusão do sistema online, que interconectou as diversas agências dos bancos em tempo real. Logo mais, vieram os caixas eletrônicos de autoatendimento e os cartões magnéticos. Surgiu ainda a possibilidade de realização de algumas operações via telefone - era o início do serviço de call center. De maneira geral, o esforço de interligar as agências e de desenvolver canais fora delas para atender os clientes pode ser sintetizado pela ideia, muito difundida à época, de que era necessário que o cliente deixasse de ser cliente de uma agência e se transformasse em cliente de um banco.

Já no final dos anos 1980 e início dos anos 1990, a automatização extrapolou os limites espaciais das agências, e as transferências eletrônicas dos dados passaram a ser feitas também a partir de residências e escritórios (home e office banking). Com a introdução dos caixas automáticos e dos cartões magnéticos, tornou-se possível a criação de estruturas compartilhadas entre os bancos, a exemplo do "Banco 24 horas" (Fonseca, Meirelles e Diniz, 2010).

Diferentemente das décadas anteriores, em que as inovações tinham lugar no interior dos bancos, nas chamadas retaguardas ou back-offices, a partir dos anos 1980 as transformações tornaram-se visíveis e mesmo disponíveis aos clientes. De lá para cá, a maior parte dos investimentos em inovação tem se voltado ao desenvolvimento de canais de comunicação entre o banco e seus clientes e usuários, assim como à realização de operações financeiras fora do que se entende como o espaço bancário por excelência: as agências.

Para Segnini, o investimento em automação foi movido por três estímulos principais: i) aumento da fatia de mercado (competição interbancária); ii) agilização do fluxo de informações para a administração; e iii) redução de custos. Dessa forma, além de agilizar e racionalizar os processos realizados pela retaguarda dos bancos, como fizeram os CPDs na década de 1960, a automação dos anos 1980 constituía-se como sistema de apoio à tomada de decisões, e por fim, de- 
senvolvia-se também como instrumento de marketing - na medida em que as inovações disponíveis atraíam clientes e aumentavam a fatia de mercado dos bancos tecnologicamente atualizados (Segnini, 1998).

Os anos 1990 são identificados, dentre outros aspectos, pela difusão generalizada dos caixas automáticos, dentro e fora das agências bancárias. Nesse período, diversas inovações de hardware, software e de redes de comunicação de dados foram introduzidas nas agências e nos departamentos administrativos dos bancos. A partir da segunda metade da década, uma das prioridades adotadas foi a diversificação do mix de produtos e serviços financeiros ofertados. E em 1996 tiveram início as primeiras transações bancárias pela internet - canal que deslanchou na década seguinte.

A chegada da internet alterou sobremaneira as infraestruturas tecnológicas dos bancos. Não apenas em relação à "internet tradicional, para os clientes, mas à internet como plataforma de desenvolvimento de novos negócios, que integra clientes, parceiros e fornecedores em um grande ecossistema" (Fonseca, Meirelles e Diniz, 2010, p. 258). Foi esse o salto dado pela internet: enquanto no fim dos anos 1990 ela consistia num canal de venda de serviços, poucos anos mais tarde plataformas internas de comunicação dos bancos eram inteiramente organizadas por intranets.

O desenvolvimento de novos canais de interação com os clientes, a ampliação do espaço de armazenamento de dados e a garantia da segurança na rede são desafios que, em grande parte, vem pautando a estratégia das instituições bancárias nas décadas de 2000 e 2010.

Do ponto de vista da organização e dos processos de trabalho, uma inovação importante do período foi a instituição dos correspondentes bancários. Estes são estabelecimentos como lotéricas, supermercados, correios e vários outros, que, conectados online com os bancos, prestam serviços de recebimentos de contas, saques, transferências, etc. Trata-se de um processo de externalização do trabalho bancário, que passa a ser realizado fora da agência e por trabalhadores que não integram a categoria bancária propriamente dita. Os correspondentes foram importantes agentes do processo de bancarização vivenciado nas primeiras décadas do século XXI no Brasil. Atualmente 
mais de $90 \%$ da população do país é considerada bancarizada (Febraban, 2017a) e o número de contas correntes e contas poupança ${ }^{4}$ é de 161 e 168 milhões, respectivamente (Febraban, 2018). Estimulado por esse movimento, o número de correspondentes bancários registrado em 2017 foi de 341,3 mil unidades, sendo 161,4 mil (47\%) na região Sudeste; 71,4 mil (21\%) no Sul; 63,4 mil (18,5\%) no Nordeste; 29,5 mil (8,5\%) no Centro-Oeste; e 15,6 mil (5\%) no Norte (Febraban, 2018). Na primeira década e meia do século XXI, os postos de atendimento dos correspondentes cresceram $1.475 \%$, passando de 18.653 para 293.767 unidades entre 2001 e 2015 (Contraf-Cut, 2017).

Outro exemplo de externalização do trabalho bancário são as centrais de teleatendimento, os call centers dos bancos. A origem deste tipo de serviço remonta ao início da década de 1990, auge da inflação, época das aplicações de overnight, em que os clientes telefonavam para os bancos para consultar saldo, aplicar e desaplicar, jogando com a rentabilidade financeira dos investimentos de curtíssimo prazo. Nesse contexto, os bancos tiveram a ideia de disponibilizar consultas aos dados bancários na modalidade 24x7, ou seja, 24 horas por dia, nos 7 dias da semana. Porém, o crescimento da demanda por este canal foi acompanhado pelo encarecimento do serviço. Foi então necessário buscar formas de rentabilizar o uso dos call centers, e estes tornaram-se canal de venda de produtos. Passou-se então a aplicar os princípios do credit scoring, calculando as probabilidades dos clientes tomarem empréstimos com base no histórico de movimentações de conta. Com as probabilidades em mãos, os bancos ofertavam os créditos aos clientes quando estes ligavam para o teleatendimento (Fonseca, Meirelles e Diniz, 2010).

Estas duas formas de externalização, os correspondentes bancários e as centrais de teleatendimento, permitem a terceirização de três atividades fundamentais exercidas pelos bancos: a intermediação financeira; o recebimento de pagamentos; e a concessão de crédito. Trata-se, portanto, da terceirização de parte das áreas comercial e negocial das instituições bancárias.

4 Cabe notar que em 2016 havia 200 milhões de contas poupança no país. No ano seguinte, foram registradas 168 milhões, ou 32 milhões de contas a menos, o que pode ser explicado pelo aumento do desemprego e da informalidade e pela redução do crescimento econômico registrado no período. 
$\mathrm{O}$ advento dos canais digitais teve início com o home e o office banking, que inicialmente conectavam os personal computers (PCs) da casa ou do trabalho ao sistema do banco. Este canal foi aprimorado para o que conhecemos hoje como o internet e o mobile banking, canais que ampliaram ainda mais os espaços de comercialização dos produtos e serviços bancários. Em 2016, uma em cada cinco transações bancárias foi realizada por estes dois canais. Contudo, em razão da "facilidade, personalização e usabilidade", a preferência dos clientes têm sido cada vez mais para acesso via smartphones (mobile banking), em detrimento do acesso por computadores (internet banking). Tanto é assim que o uso do mobile $e^{5}$ quadruplicou nos últimos três anos, chegando a 25,6 bilhões de transações ${ }^{6}$ em 2017 , ou $35 \%$ do total de 71,8 bilhões de transações, o maior da série histórica acompanhada pela Federação Brasileira de Bancos, a Febraban (Febraban, 2018).

As chamadas "agências digitais" são resultado do uso cada vez mais intensivo dos canais de atendimento digital. Trata-se de espaços ou fóruns inteiramente digitais de atendimento aos clientes. Em 2017, já somavam 373 (Febraban, 2018) e há inclusive instituições bancárias completamente digitais, que não possuem nenhuma agência física, como é o caso do Banco Original. De fato, os bancos parecem comprometidos com esta tendência, pois em 2015 o Banco Itaú anunciou um plano de fechamento de metade de suas agências, almejando substituí-las por agências digitais em até 10 anos (Contraf-Cut, 2017).

Atualmente, mais da metade das transações financeiras é realizada pelos canais digitais (57\%) e os novos investimentos têm sido direcionados para o aprimoramento da segurança, da rapidez e da facilidade das operações. Alguns exemplos são a biometria e outras tecnologias ligadas ao big data, como blockchain ${ }^{7}$; analytics ${ }^{8}$; near

$5 \mathrm{Na}$ linguagem dos bancos, os usuários que utilizam os smartphones para $80 \%$ ou mais das operações financeiras são considerados heavy users. Em 2017, 15,6 milhões das contas movimentadas por celulares era dos heavy users, o que equivale a 35\% do total das contas de mobile (Febraban, 2018).

$6 \mathrm{O}$ uso do mobile ainda é majoritariamente destinado a transações não financeiras (consultas de saldo e extrato, por exemplo). Das 25,6 bilhões de transações realizadas por meios dos smartphones em 2017, 1,7 bilhão eram financeiras e 23,9 bilhões eram transações não financeiras (Febraban, 2018).

$7 \mathrm{O}$ sistema de registro de informações digitais blockchain funciona como um "livro de caixa criptografado", no qual todos os registros são imutáveis e enviados às partes envolvidas em tempo real. Permite o armazenamento das informações das negociações em ambientes virtuais seguros e de forma permanente, evitando fraudes e conferindo credibilidade às informações.

8 Exploração e manuseio dos dados disponíveis nos big data dos bancos ou de dados compartilhados por outras empresas com o objetivo de conhecer hábitos de consumo e perfis dos clientes para 
field communication ${ }^{9}$; e a Internet das Coisas ${ }^{10}$.

A versatilidade do atendimento pelos canais digitais fora da agência possibilita ao cliente realizar qualquer tarefa e operação antes realizada dentro dela, à exceção do saque (emissão de notas). Toda a movimentação financeira e, mais recentemente, até mesmo a contratação de crédito pode ser feita sem o auxílio de um trabalhador bancário, a qualquer hora do dia ou da noite e em qualquer lugar (com acesso à internet). É o retrato do fenômeno analisado por Giddens (1991), de compressão do espaço-tempo, no qual "o consumidor pode viajar o mundo e resolver tudo com um aparelho que pode ser levado para todos os lugares. Ou pode deixar todas as contas pagas e transferências agendadas antes de fazer a viagem" (Febraban, 2017a, p. 19).

Os caixas automáticos $\left(\mathrm{ATMs}^{11}\right)$ vem sendo aprimorados e em 2016 78,8\% deles estavam adaptados para pessoas com deficiência (Febraban, 2017a). No entanto, por conta da emergência e comodidade oferecida pelos demais canais seu uso vem caindo. De de 2014, quando as máquinas ATMs atingiram seu pico, a 2017, o número de ATMs reduziu de 184 para 170 mil $^{12}$ unidades no país (Febraban, 2018). Em relação ao número de operações, o pico de utilização também foi registrado em 2014, com 10,2 bilhões, porém a redução foi pequena e nos dois anos seguintes também foram registradas 10 bilhões de transações. Pelo fato de ser o único canal que permite o saque monetário, não há expectativa de queda expressiva no futuro próximo. Porém, cabe notar que a própria utilização dos canais digitais para fins de movimentação financeira, em especial o uso das máquinas de pagamento de débito e crédito $^{13}$ no comércio, reduz a necessidade de transacionar moeda no dia a dia.

posterior oferta de produtos e serviços.

9 O sistema de near field communication (NFC) é uma espécie de "pagamento sem contato", que permite aos clientes realizar pagamento por meio da aproximação dos smartphones das máquinas de débito e crédito, sem a necessidade do uso do plástico dos cartões.

10 Mais conhecida pelo termo em inglês Internet of Things (IoT), esta tecnologia conecta objetos do dia a dia à internet e permite, dentre outras coisas, seu controle remoto.

11 Automated Teller Machine(ou máquinas automáticas falantes), também conhecido como terminal de autoatendimento (TAA).

12 Este número equivale a 109 ATMs para cada 100 mil adultos, o que coloca o Brasil em 4o lugar no levantamento do número de ATMs feito pelo Banco Mundial. Os primeiros da lista são Canadá (223); do Reino Unidos (129) e do Japão (128) (Febraban, 2018).

13 Denominadas de Points of Sale (POS) no jargão bancário. 
Devido a todas estas transformações, as agências bancárias físicas vivem um momento de mudança em relação ao tipo de serviço preferencialmente ofertado. Apesar da migração de clientes para os canais digitais, foram registradas 5,3 bilhões de transações com movimentação financeira nas agências em 2016 (aumento de 35\% em relação a 2011). O número de agências físicas gira em torno de 22 mil unidades em todo o país, mas apresenta tendência decrescente: de 2016 para 2017 houve redução de 23,4 para 21,8 mil agências físicas ${ }^{14}$ (Febraban, 2018). Ao invés de extinguí-las por completo, o plano dos bancos parece ser reduzir parte de suas unidades e implementar nas restantes o que seriam as "agências do futuro", ficando a função dos bancários mais focada em atividades ligadas à gestão dos negócios e consultas de investimento.

Vê-se, portanto, que a chegada das inovações alterou sobremaneira as atividades bancárias, bem como as relações de trabalho nos bancos. Mais do que isso, as tecnologias bancárias vem alterando a organização e o ritmo da sociedade como um todo. São constitutivas de novas dinâmicas sociais. Formam o que Latour (2011) chama de redes sociotécnicas, que envolvem um conjunto de atores humanos e não humanos - neste caso banqueiros, executivos dos bancos, trabalhadores, clientes e usuários; e os artefatos tecnológicos como máquinas, softwares, computadores e telefones celulares, respectivamente. Nesse mesmo sentido, Feenberg aponta que a relação com as tecnologias molda novos estilos de vida: "padrões de desenho técnico definem partes principais do ambiente social, tais como espaços urbanos e construções, ambientes de trabalho e expectativas médicas, estilos de vida e assim por diante" (Feenberg, 2010, p. 122).

Valores e interesses políticos, econômicos e culturais constituem as redes sociotécnicas, de modo que não é possível distinguir - concreta e analiticamente - tecnologia, ciência e sociedade ${ }^{15}$. Qualquer mudança nos novos estilos de vida referidos por Feenberg, ou no sistema de princípios ligado à produção da tecnologia é, portanto,

14 A distribuição regional das agências é de $53 \%$ no Sudeste; $18 \%$ no Sul; $16 \%$ no Nordeste; $8 \%$ no Centro-Oeste; e $5 \%$ na região Norte do país.

15 A separação analítica entre tecnologia e sociedade é característica do construtivismo dos Estudos Sociais da Ciência e da Tecnologia. Autores como Winner, 1986; Bijker; Hughes; e Pinch, 1989; Figueiredo, 1989; dentre outros criticam a noção de neutralidade dos artefatos tecnológicos argumentando que valores sociais permeiam o desenvolvimento das tecnologias. Contudo, conforme aponta Latour, acabam por combater o determinismo tecnológico com outro tipo de determinismo, desta vez de caráter social, cultural ou econômico. 
dependente e indissociável de mudanças conjuntas nas formas de organização e hierarquização social.

As redes sociotécnicas formadas no âmbito dos bancos criam conexões inseparáveis entre trabalhadores, máquinas e softwares. Esta atuação coletiva faz com que nenhuma das partes possa prescindir das demais, conforme aponta Sanches:

Outras tarefas e funções precisam ser exercidas para que o processo de automação se viabilize. Em outras palavras é preciso considerar que alguém programou o sistema, deverá acompanhar sua instalação, manutenção e atualizações constantes neste meio. Também é preciso relevar que a máquina por si só não funciona, caso exemplar dos Caixas Eletrônicos, em que alguém os controla remotamente como também presencialmente se faz necessária a manutenção; o abastecimento de insumos básicos (dinheiro, bobina de papel, tinta, envelopes); a higienização das partes internas do maquinário; o recolhimento de envelopes de depósito; o transporte do dinheiro e envelopes; o processamento de cheques que serão validados concluindo assim as operações iniciadas pelos clientes por este meio (Sanches, 2012, p. 19).

A interdependência se manifesta também na relação cotidiana entre bancários e usuários das plataformas digitais, com questões que a própria tecnologia faz surgir. Isto é, mesmo clientes que preferem utilizar os caixas automáticos ou os canais digitais se dirigem às agências em busca de suporte e auxílio no uso das tecnologias, em operações mais simples, como os saques, no uso da biometria ou mesmo no manuseio dos aplicativos bancários para smartphones.

Este processo retrata o que Giddens denominou de sistemas -peritos. Com o aprofundamento da modernidade, boa parte dos ambientes material e social dos dias de hoje é baseado em sistemas de excelência técnica ou competência profissional. Tais sistemas atuam como mecanismos de desencaixe, na medida em que removem as relações sociais das imediações de seus contextos originais ou primeiros. Assim, "a cada vez que alguém saca dinheiro do banco ou faz um depósito, [...] está implicitamente reconhecendo as grandes 
áreas de ações e eventos seguros e coordenados que tornam possível a vida social moderna" (Giddens, 1991, p.116).

Nesse sentido, o caso das tecnologias bancárias e seus efeitos sobre os trabalhadores, clientes, usuários e sobre a sociedade de maneira geral é exemplar, pois as mudanças impressas pelas novas tecnologias acompanham, ao mesmo tempo em que propiciam, o aprimoramento de operações e relações baseadas nos sistemas-peritos.

A seção a seguir analisa os efeitos das tecnologias sobre o cotidiano bancário e mapeia as formas de controle do trabalho dentro e fora das agências, as novas formas de exploração do trabalho bancário e sua coexistência e complementaridade com formas de exploração mais antigas. São também analisados os impactos das inovações tecnológicas sobre o emprego bancário e sobre o mercado de trabalho do ramo financeiro de maneira geral.

\section{TECNOLOGIA, PROCESSOS E RELAÇÕES DE TRABA- LHO NOS BANCOS}

A chegada de máquinas - como as máquinas de datilografia, as calculadoras e as cartelas contábeis -, seguidas dos sistemas computadorizados, alterou não apenas a própria arquitetura das agências bancárias, como também a distribuição dos trabalhadores dentro delas.

De modo geral, as inovações tecnológicas introduzidas até o surgimento da informática e dos sistemas online intensificaram o trabalho por meio da sua divisão, fragmentação e especialização e da transferência da força física do trabalhador para a máquina.

Com a chegada dos ATMs, da internet e do mobile banking, os próprios clientes passaram a exercer atividades antes desempenhadas por bancários, ou seja, passaram a trabalhar para si e ainda pagar tarifas para cada uma das operações efetuadas (Sanches, 2012). São as chamadas tecnologias self-service, em que os clientes digitam dados; manuseiam cartões eletrônicos; escaneiam códigos de barra; interagem com serviços de resposta audível (voz eletrônica) das centrais de atendimento telefônico; e seguem orientações de procedimentos dos ATMs e/ou das plataformas digitais. 
Em decorrência disso, diversos autores (Jinkings, 1995; 2002; Netz, 2005; Segnini, 1998; Soares 2013; e outros) analisam o processo de fragmentação dos trabalhadores e apontam que enquanto uns concebem, planejam e controlam atividades, outros simplesmente as executam - e executam tarefas práticas e simplificadas, pouco valorizadas, tornando-se mão-de-obra facilmente substituível.

Semelhante ao processo analisado por Sennet (2004) a respeito da transição dos ofícios para as manufaturas, Grun (1986) analisa como o "saber do métier" bancário foi se esvaziando de conteúdo. Para Grun, este "saber" já vinha sendo apropriado pela direção dos bancos desde o início da mecanização e esta apropriação intensificou-se ainda mais com a introdução da informática. Os conhecimentos nas áreas de contabilidade e matemática e as qualidades de lealdade e honestidade, logo mais deixaram de integrar o perfil valorizado e desejado de bancário (Segnini, 1998; Netz, 2005). De acordo com Grun (1986), o ofício do trabalho bancário teria passado por um processo de captura pela automação ao longo do tempo.

Há, porém, interpretações que problematizam a tese da fragmentação. Para Oliveira (2014), o conteúdo do trabalho bancário não se alterou com o tempo; permaneceu o mesmo desde os primórdios da atividade: realizar transferências contábeis de uma conta a outra. $\mathrm{O}$ autor argumenta que as mudanças recaem somente sobre a forma com que o trabalho é executado. A introdução de ferramentas tecnológicas no setor bancário - desde a máquina de escrever, nos anos 1930, passando pela máquina de calcular e pelas máquinas para a feitura das cartelas contábeis, nos anos 1940 e 1950 respectivamente, culminando com a constituição dos CPDs nos anos 1960 - teria alterado a forma, mas não o conteúdo do trabalho bancário. Os serviços contábeis dos bancos, como o livro-caixa e o diário-caixa, posteriormente substituídos pelas cartelas contábeis, os cálculos de juros, a atualização de saldos, etc. foram progressivamente sendo alterados em seu modo de execução, mas mantiveram sua finalidade. "Parece-nos, portanto, que um trabalho estritamente contábil deixa pouca margem para soluções criativas, uma vez que não há criatividade que dê conta de resolver um erro na atualização de um saldo ou no controle de um caixa: os 
números fecham ou não fecham". (Oliveira, 2014, p.108).

Nesse sentido, o autor entende que o argumento da separação entre concepção e execução tem um quê de romantização. De fato, análises de períodos distintos discutem como o trabalhador bancário perdeu sua autonomia no banco, assim como pontuam que as possibilidades de construção de uma carreira de longa duração são cada vez mais escassas. De acordo com esta linha de interpretação, o trabalho bancário teria se distanciado cada vez mais do "ofício", aqui tomado como um tipo ideal.

Este tipo de análise traz uma certa idealização do trabalho bancário de antes, quando comparado com o trabalho do presente seja qual for o presente, a década de 1980 ou os dias de hoje. Cada geração avalia que no "seu" passado a profissão exigia mais conhecimentos específicos e permitia maior autonomia e mobilidade na carreira. O presente de cada autor (ou entrevistado) é, via de regra, identificado como um período de esvaziamento do trabalhador e de menor identificação deste com a instituição, até mesmo em função da desestruturação das carreiras, na forma como existiam antes.

De fato, todos os trabalhadores bancários são, de maneira cada vez mais frequente, submetidos a formas de intensificação do trabalho, isto é, de extração de mais-valia relativa. Para a parte do contingente bancário que realiza tarefas mais mecanizadas (caso da separação de cheques), a exigência de alta qualificação em termos de títulos "atua como critério de privilégio para os que ainda estão empregados" (Netz, 2005, p. 6), pois a demanda real do trabalho é cada vez mais simples. Já da parcela dos bancários que ocupa os postos semiqualificados são requeridas alta concentração e responsabilidade, como ocorre com os caixas. Em ambos os casos uma das características centrais das cobranças é a agilidade na execução das tarefas.

Apesar de executar tarefas mais simples, o caixa bancário executa hoje, do próprio guichê, um vasto conjunto de tarefas antes realizadas na retaguarda. O sistema online lhe deu acesso a dados que lhe permitem operar diretamente de seu terminal. Agora, a transação tem início e fim no próprio caixa. Os dados disponíveis sobre a produtividade média dos bancos revelam o aumento da carga individual de trabalho: "enquanto em 2000 havia uma média de 159 clientes para 
cada bancário e eram realizadas 49 mil operações anuais, em 2010 o número de clientes passou para 291 por bancário e as operações aumentaram para 113 mil per capita" (Machado e Amorim, 2012, p. 182).

Com a automação, o tempo para a execução das tarefas tornou-se pré-determinado e mais controlável, levando ao aumento das cobranças por cotas de produtividade (Soares, 2013). Sendo assim, "ao longo da jornada de trabalho podem ser disponibilizados relatórios completos e detalhados da atividade produtiva, seja por pessoa ou por locais de trabalho, incluindo os serviços que estão terceirizados" (Sanches, 2012, p. 16). Tais relatórios são utilizados como referência tanto para premiações quanto para a exposição negativa daqueles trabalhadores que obtiveram produção inferior ao esperado.

As formas de exprimir as cobranças também se alteraram. Celulares, e-mails e outros meios de comunicação vem sendo utilizados. Este fenômeno aumenta forçosamente a disponibilidade dos funcionários para o empregador, "fazendo com que o tempo de trabalho 'invada' o de 'não-trabalho'" (Soares, 2013, p. 65). Atualmente há bancos que oferecem atendimento personalizado com horário bastante superior ao expediente bancário, em alguns casos das $7 \mathrm{~h}$ às $0 \mathrm{~h}$, em outros das $8 \mathrm{~h}$ às $22 \mathrm{~h}$. Nesses casos, os trabalhadores ficam a disposição em sistema de home office ou, por escala, em prédios administrativos, para o atendimento de clientes via plataformas digitais.

Pelo fato de poderem cumprir jornadas de trabalho superiores a seis horas diárias sem o recebimento de horas extras, o número de postos de chefias e demais cargos comissionados cresceu enormemente a partir dos anos 1980. Há casos de funcionários que, na prática, não realizam funções e não têm responsabilidades de chefe, mas são "promovidos" a cargos de confiança ou chefia, pois este é um artifício empregado pelos bancos para burlar a legislação e reduzir gastos com salários, uma vez que a gratificação ou comissão recebida é inferior ao valor que seria devido com as horas extras.

Os sinais de simplificação de tarefas e a consequente desqualificação dos trabalhadores que as executam ocorre em âmbito que extrapola o dos bancários propriamente ditos e atinge, fundamentalmente, aqueles trabalhadores que exercem atividades tipicamente 
bancárias mas não são assim reconhecidos. São eles os atendentes de correspondentes bancários e o enorme contingente de trabalhadores terceirizados do setor financeiro, que vão desde vigilantes e funcionários da limpeza até trabalhadores dos setores de compensação, recursos humanos e teleatendimento.

Este conjunto de transformações nos dá pistas sobre o que ocorreu "na cena do trabalho bancário", para usar expressão de Sanches (2012), quando da chegada da informática. Muitos trabalhadores perderam seu emprego - principalmente aqueles pertencentes à retaguarda - devido à extinção de algumas funções e da redução de trabalho vivo demandado para a realização de outras tantas funções. Ao mesmo tempo, novas funções foram criadas ou expandidas - caso dos auxiliares de autoatendimento; dos operadores de teleatendimento; dos gerentes de contas e assistentes de gerência - assim como surgiram novas formas de inserção no mercado de trabalho do setor financeiro, cujo caso mais evidente são os terceirizados (Sanches, 2017).

Processo semelhante havia ocorrido quando surgiram os primeiros computadores nos bancos. Foram criadas então as funções de digitadores e conferentes, responsáveis pela entrada e pela conferência de dados, tarefas bastante simplificadas e padronizadas. Comparando as pesquisas de perfil dos bancários, realizadas pelo Dieese em 1980 e 1992, Jinkings (1995) verificou a diminuição de escriturários e das chefias intermediárias, bem como dos trabalhadores envolvidos nos serviços operacionais e administrativos, ao passo que cresceu o número de técnicos e gerentes especializados em informática e no atendimento ao cliente. Simultaneamente, os cargos técnicos mais especializados iam sendo incorporados aos quadros de carreira dos bancos, nas funções de operação, programação e análise computacional. Com a complexificação das tecnologias, os próprios técnicos, que quando da introdução dos primeiros computadores eram responsáveis pelo todo da máquina, passaram a especializar-se. Surgiram as funções de operador, programador, analista, dentre outras.

Mais recentemente alçados à categoria de operadores, os clientes também ocupam posição de destaque no sistema de cobrança e pressão sobre os trabalhadores. O controle do cliente começa 
como pressão simbólica para a realização do trabalho no espaço e no tempo esperados, assim como na qualidade por ele requerida. Entretanto, as formas de controle extrapolam a dimensão simbólica e incluem formas de regulação formal e informal. A primeira está presente nas normas da empresa, no código do consumidor e em legislações específicas ${ }^{16}$. A segunda apela para a ética, combinada às emoções do trabalhador, incluindo aspectos como atenção, cortesia e "bons costumes". Em caso de discordância ou desacerto entre as partes, as pressões podem chegar à esfera jurídica e não se exclui a possibilidade do uso de violência física ou simbólica por parte dos clientes ou dos trabalhadores (La Garza, 2011).

A intensificação da cobrança sobre os bancários foi acompanhada, portanto, pelo aumento da diversidade das formas de efetuá -la. As discussões cada vez mais frequentes acerca do tema do assédio moral estão diretamente ligadas à imposição de metas abusivas e às exigências de polivalência. Em linhas gerais, esta forma de assédio consiste em atos de constrangimento vividos pelo trabalhador, partem de superiores ou colegas e provocam situações vexatórias e humilhantes durante o trabalho.

Nessa mesma direção, cabe ressaltar a multiplicação dos registros de doenças físicas e psíquicas entre os bancários. Segundo Soares (2013), as reclamações de tensão, estresse, ansiedade e nervosismo são generalizadas entre os bancários, que, segundo a Previdência Social, é uma das categorias mais atingidas por casos de adoecimentos no trabalho:

Somente em 2009, foram registrados 7.717 casos de empregados do setor bancário que adquiriram LER no exercício de suas funções de trabalho. Em 2010, 1.200 bancários em média foram afastados a cada mês por auxílio-doença concedido pelo INSS, metade dos quais devido à contração de LER ou de transtornos mentais. Os transtornos mentais vão desde uma pequena depressão até tentativas de suicídio, passando por transtorno obsessivo compulsivo, transtorno bipolar, síndrome do pânico, perda de juízo, etc (Soares, 2013, p. 58).

16 Diversos municípios possuem leis que versam sobre o tempo de espera na fila dos bancos. 
A introdução das novas tecnologias possibilitou a ampliação das redes sociotécnicas dos bancos, que se tornaram mais heterogêneas e ampliaram seu alcance espacial. Isso ocorreu sobretudo com os processos de terceirização, os quais inauguraram novas possibilidades de exploração e controle do trabalho. Sanches $(2006 ; 2017)$ e Oliveira (2014) destacam que, de início - anos 1980 até meados da década de 1990 - a terceirização no sistema bancário, além da segurança e da limpeza, restringia-se às atividades de manutenção de prédios, transporte de malotes e alimentação. Até então respeitava-se o princípio da especialização e os bancos contratavam outras empresas somente para o cumprimento de tarefas que não pertenciam à sua atividadefim. Logo mais, já na segunda metade da década de 1990, foram terceirizados outros setores dos bancos, desta vez da área administrativa, caso da retaguarda e da compensação de cheques. Por fim, mais recentemente, até mesmo a área comercial/negocial dos bancos - telefonia, recepção, teleatendimento, cobrança, análise de crédito, tecnologia da informação - está sendo terceirizada, seja por meio da contratação desse tipo de mão de obra, seja pelo repasse dos serviços bancários para empresas terceiras (Oliveira, 2014). Com a aprovação da Lei da Terceirização (Lei n.13.429/2017) e da Reforma Trabalhista (Lei n. 13.467/2017), não é mais possível a contestação legal destas práticas, e o número e as formas de terceirização devem crescer ainda mais.

Seja qual for a modalidade da terceirização, pode-se constatar que grande parte desses trabalhadores fica submetida à condições e regimes de trabalho inferiores àqueles encontrados nas agências e em outras repartições dos bancos. Segundo o estudo do Departamento Intersindical de Estatística e Estudos Socioeconômicas (DIEESE), a desigualdade entre bancários tradicionais e terceirizados manifesta-se, dentre outros aspectos, em relação à remuneração; à jornada de trabalho; e à rotatividade no emprego: enquanto os bancários têm jornada (oficial) de 30 horas semanais, os terceirizados têm contrato de 44 horas por semana. Seus salários representam, em média, um quarto do salário da categoria bancária - o terceirizado recebe 3,55 reais por hora trabalhada, enquanto um bancário recebe 12,44 reais pelo mesmo período de trabalho. E o tempo médio de permanência 
no emprego dos terceirizados é de 2,6 anos, enquanto o dos bancários é de 5,8 anos (Dieese, 2011).

As novas tecnologias, associadas às novas formas de contratação alteraram a configuração do mercado de trabalho bancário. A seguir são analisados os efeitos destas transformações sobre o emprego e a dinâmica do mercado de trabalho bancário e do ramo financeiro de modo geral.

\subsection{Tecnologia, emprego e mercado de trabalho}

Os investimentos em automação bancária, voltados para os ganhos de produtividade, tem como um de seus focos principais a redução do custo de mão de obra. Para tanto, os bancos buscam desenvolver tecnologias que possibilitem a substituição do trabalho humano por máquinas e softwares, combinada com a intensificação e com controles mais rígidos do trabalho.

Entretanto, o caso do Brasil no século XXI evidencia que a análise dos efeitos das tecnologias sobre o emprego deve considerar o mercado de trabalho em diálogo com a conjuntura econômica e política. O baixo crescimento econômico e as altas taxas de informalidade e de desemprego dos anos 1990 no Brasil, foram também combinados com o aumento da concentração bancária e com a redução do número de bancos públicos. Atualmente o sistema bancário nacional se vê majoritariamente concentrado em cinco instituições: Itaú, Bradesco, Santander, Banco do Brasil e Caixa Econômica Federal ${ }^{17}$. Os investimentos em automação no período inflacionário e aqueles decorrentes do advento da internet são mais uma dentre as diversas variáveis que atuaram sobre o emprego. Todas estas transformações influenciaram o índice de emprego da categoria bancária, que reduziu de 732 mil para 402 mil trabalhadores entre 1990 e 2000 (Sanches, 2012).

Nos anos 2000, o cenário macroeconômico brasileiro mudou. As taxas de informalidade e de desemprego caíram e numerosas parcelas da população foram incluídas no sistema financeiro por meio da bancarização. Os bancos ampliaram sua rede de aten-

17 Estes cinco bancos concentram $69 \%$ dos ativos e $85 \%$ dos depósitos totais do setor (Febraban,2017b). 
dimento bancário, sobretudo na modalidade dos correspondentes, mas também abriram novas agências e postos de atendimento. Por conta disso, o emprego bancário cresceu. Outra característica significativa do período diz respeito às mudanças relativas à regulação do mercado de trabalho, que contribuíram para conquistas sindicais importantes no período como: manutenção da remuneração integral para trabalhadores afastados por problemas de saúde em período de perícia (2012); termo de entendimento com finalidade de reduzir os adoecimentos (2015); Grupo de Trabalho (2006) e Protocolo (2011) de prevenção de conflitos no ambiente de trabalho bancário; extensão de direitos aos casais homoafetivos (2004 para os trabalhadores da Caixa Econômica Federal, logo seguida pelos demais bancos); Programa de Capacitação Profissional e Inclusão de Pessoas com Deficiência no Setor Bancário (2008); ampliação da licença-maternidade de 120 para 180 dias (2009), agora extendida aos parceiros homoafetivos; ampliação da licença paternidade de 5 para 20 dias (2016); adesão dos bancos públicos aos acordos coletivos nacionais ${ }^{18}$; direito ao acompanhamento médico psicológico para trabalhadores vítimas de assaltos e sequestros (2010); medida sobre monitoramento de resultados, que impede a divulgação do desempenho individual de cada bancário abertamente nos bancos e entre os colegas de trabalho (2010); dentre muitas outras (Dulci, 2015).

O ambiente favorável dos anos 2000 materializou-se no crescimento da categoria que, em 2014, chegou a somar 512.186 bancários, ao passo que o registro dos trabalhadores no ramo financeiro como um todo foi de 1.043.620 no mesmo ano. O número de sindicalizados também cresceu, porém em quantidade inferior ao aumento da categoria, o que resultou na redução da taxa de sindicalização, que passou de 45,5\% para 40,4\% entre 2002 e 2015. (Contraf-Cut, 2017).

É neste contexto que se dá a criação Confederação nacional dos Trabalhadores do Ramo Financeiro (Contraf), no ano de 2006, em substituição à Confederação Nacional dos Bancários (CNB) e uma tentativa de dar resposta aos desafios colocados ao conjunto dos tra-

18 Os trabalhadores dos bancos privados negociam suas Convenções Coletivas de Trabalho em âmbito nacional desde 1992. Em 2005 o Banco do Brasil aderiu à negociação coletiva nacional e no ano seguinte (2006) foi a vez da Caixa Econômica Federal. 
balhadores do setor. Assim, a criação da Contraf-CUT não foi apenas uma forma de suceder à antiga $\mathrm{CNB}$, mas uma aposta na criação de um espaço que congrega interesses dos diversos grupos de trabalhadores que compõem o ramo financeiro. Uma tentativa de representar, organizar e mobilizar os trabalhadores para além da unidade "categoria profissional". Isto é, uma tentativa de superar a lógica corporativista da estrutura sindical brasileira vigente desde a Era Vargas.

A tendência de expansão da economia foi interrompida em meados da década de 2010, com a redução do crescimento e o aumento do desemprego e da informalidade. No mesmo sentido, alterações na correlação de forças entre capital e trabalho levaram ao acirramento das tensões entre bancos e bancários, manifesto em perdas nas Convenções Coletivas de Trabalho e no índice de emprego bancário já no início dos anos 2010. A tendência reversiva sobre o emprego foi detectada a partir de 2013. E entre o início de 2013 e meados de 2017 foram extintos mais de 50 mil postos de trabalho ${ }^{19}$ nos bancos. Parcela significativa das perdas cabe aos planos de demissão voluntária ou incentivada, lançados pelos bancos públicos - Banco do Brasil em 2015 e Caixa Econômica Federal em 2017 -, resgatando uma prática comum dos anos 1990 (Contraf-Cut, 2017).

A tabela 1 a seguir evidencia a dinâmica deste início de século XXI aqui analisada.

Tabela 1

\begin{tabular}{|c|c|c|c|c|c|}
\hline \multicolumn{6}{|c|}{$\begin{array}{c}\text { Taxa de crescimento econômico (PIB), variação do emprego entre bancários } \\
\text { e trabalhadores do ramo financeiro, taxa de sindicalização e montante de } \\
\text { investimento em inovação bancária no Brasil (2002-2015) }\end{array}$} \\
\hline Ano & $\Delta$ PIB & $\begin{array}{c}\text { Emprego } \\
\text { bancário }\end{array}$ & $\begin{array}{c}\text { Empre- } \\
\text { gos ramo } \\
\text { finan- } \\
\text { ceiro }\end{array}$ & $\begin{array}{c}\text { Taxa de sindica- } \\
\text { lização (\%) }\end{array}$ & $\begin{array}{c}\text { Investimento tecnologia } \\
\text { (R \$ bi) }\end{array}$ \\
\hline 2002 & 3,05 & 398.098 & 739.894 & 45,5 & 3,5 \\
\hline 2003 & 1,14 & 399.183 & 760.446 & 47 & - \\
\hline 2004 & 5,76 & 405.036 & 745.696 & 45,8 & - \\
\hline 2005 & 3,2 & 420.036 & 742.241 & 44,9 & - \\
\hline 2006 & 3,96 & 422.219 & 793.519 & 42 & 11,7 \\
\hline 2007 & 6,07 & 445.828 & 867.786 & 40 & \\
\hline
\end{tabular}

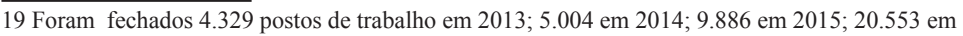
2016; e 10.752 de janeiro a junho de 2017 (Contraf-Cut, 2017). 
traços de continuidades e descontinuidades com o passado. A automação no sentido da substituição de força física por máquinas foi mais sentida até a década de 1980. A partir de então, a maior parte dos investimentos em tecnologia se dirige ao desenvolvimento das tecnologias da informação. A sofisticação tecnológica que caracteriza os bancos da atualidade elevou a importância da área de vendas, de maneira que as funções administrativas foram parcial ou integralmente substituídas por funções de comercialização de produtos e serviços.

Uma das características que chama a atenção neste início do século XXI é a combinação entre os investimentos em tecnologia e as formas de terceirização do trabalho no ramo financeiro no Brasil, a qual foi sentida a partir de tendências contraditórias. Enquanto a economia manteve uma dinâmica de crescimento com distribuição e o cenário político era favorável à organização dos trabalhadores, os efeitos do aumento dos investimentos em tecnologia e da oligopolização do setor sobre o emprego foram em parte contrabalançados pela abertura de novas agências e postos de atendimento e correspondentes bancários. Na primeira década e meia do século XXI, cresceram o lucro dos bancos (551\%), as operações de crédito (227\%), o número de correntistas $(142 \%)^{20}$ e também aumentou o emprego bancário (27\%) e o emprego no ramo financeiro (33\%) (Contraf-Cut, 2017).

A diferença entre estas taxas de crescimento - e os montantes monetários que elas representam - é o retrato da luta entre trabalho e capital, este beneficiado pelas novas tecnologias e pelas novas formas de controle dos processos de trabalho e de extração da mais valia absoluta e relativa. Quando comparados os volumes do emprego bancário atual com aquele de meados da década de 1980, a constatação das perdas torna-se evidente: em 1985 havia cerca de 1 milhão de bancários no Brasil; já em 2000, eram 400 mil, e em 2014, 512 mil (Sanches, 2012; Contraf-Cut, 2017). Apesar da redução dos postos de trabalho nos bancos propriamente ditos, cresceu o emprego no setor financeiro de modo geral, que hoje soma mais de 1 milhão de trabalhadores, contingente comparável ao número de bancários da década de 1980.

20 Variações do lucro, operações de crédito e número de correntistas calculadas entre os anos de 2001 a 2015; variação do emprego bancário e do ramo financeiro calculada entre os anos de 2002 a 2015. 
O contexto político e econômico que ora se apresenta é outro. Com a desaceleração do crescimento e, principalmente, com a interrupção do processo e dos mecanismos de distribuição de renda, o volume de emprego já se vê negativamente afetado. As formas de inserção adversa no mercado de trabalho do ramo financeiro são também estimuladas pelas alterações legislativas recentes, em especial com a Lei da Terceirização (Lei n.13.429/2017) e a chamada Reforma Trabalhista (Lei n. 13.467/2017). A diversificação de formas de contratação, de remuneração e de condições de trabalho impõem grandes desafios aos trabalhadores e às suas representações sindicais, não apenas aos bancários, mas a todos que integram o ramo financeiro, bem como os demais setores da economia.

O menor contingente de bancários, a menor concentração destes nos locais de trabalho e as novas formas de cobrança e pressão no trabalho trazem desafios relativos à organização da categoria - as mobilizações, paralisações e greves -; ao mesmo tempo em que colocam questões sobre a saúde do trabalhador, e as condições e o ambiente de trabalho. Estes impactos não podem ser isolados uns dos outros, pois chegam em conjunto, se entrelaçam e possuem consequências diversas, concomitantes e sobrepostas sobre a categoria e a vida de cada trabalhador.

Ainda que a categoria bancária tenha conquistado Convenções Coletivas de Trabalho que em muito a diferencia das demais, os bancos vem encontrando formas de burlar estes acordos e as denúncias de cobranças excessivas, assédio moral e desrespeito por patrões e clientes são uma constante. Uma das lutas mais recentes diz respeito à união dos interesses entre bancários tradicionais, terceirizados e as demais categorias do ramo financeiro. Por conta disso, em 2006 foi criada a Confederação nacional dos Trabalhadores do Ramo Financeiro (Contraf), em substituição à Confederação Nacional dos Bancários. São também diversos os esforços de renovação do repertório e da agenda de lutas, que ocorrem num espectro escalar que vai do chão da agência e do correspondente bancário ao nível global, com a atuação no âmbito dos sindicatos globais e com acordos globais com os bancos multinacionais. 
Mais transformações estão por vir, o que certamente demandará novos esforços de análise para esta já extensa agenda de pesquisas. Os desafios que ora se apresentam colocam a necessidade e mesmo a urgência de novas perguntas e elaborações teóricas para dar conta desta época de mudanças - ou desta mudança de época.

\section{REFERÊNCIAS}

ARAÚJO, Â.; CARTONI, D, \& JUSTO, C. Reestruturação produtiva e negociação coletiva nos anos 90. São Paulo: Revista Brasileira de Ciências Sociais, Vol.16, nº. 45, pp. 85-112, 2001.

BIJKER, W.; HUGHES, T.; PINCH, T. (Orgs.). The social construction of technological systems. Cambridge, MA: MIT Press; 1989.

CAMARGO, P. A evolução recente do setor bancário no Brasil. São Paulo: Cultura Acadêmica - UNESP, 2009.

CONTRAF-CUT. Lutar, defender e garantir - nenhum direito a menos. Caderno de Subsídios. 19a Conferência Nacional dos Bancários. São Paulo, 28 a 30 de jul/2017. In: http://www.contrafcut.org.br/ publicacoes/caderno-de-subsidios-para-a-19-conferencia-nacionaldos-bancarios-301f, acesso em 10 de junho de 2018.

DIEESE - Departamento Intersindical de Estatística e Estudos Socioeconômicos e CUT - Central Única dos Trabalhadores. Terceirização e desenvolvimento: Uma conta que não fecha. São Paulo, 2011. In: http://www.sinttel.org.br/downloads/dossie_ terceirizacao_cut.pdf, acesso em 20 de fevereiro de 2018.

DULCI, L. Automação bancária no Brasil do século XXI: Análises e práticas da Febraban e da Contraf-CUT. 2015. Dissertação (Mestrado em Sociologia e Antropologia). Programa de Pós-Graduação em Sociologia e Antropologia, Universidade Federal do Rio de Janeiro. Rio de Janeiro.

FEBRABAN. Pesquisa Febraban de Tecnologia Bancária, 2018. In: https:// www2.deloitte.com/content/dam/Deloitte/br/Documents/financialservices/Pesquisa-FEBRABAN-Tecnologia-Bancaria-2017.pdf, acesso em 20 de junho de 2018.

. Pesquisa Febraban de Tecnologia Bancária, 2017a. In: http:// www.ciab.org.br/download/researches/research-2017.pdf, acesso em 10 de junho de 2018.

Relatório Anual da Febraban 2017b. In: https:// relatorioanual2017.febraban.org.br/pt/FEBRABAN_RA_17.pdf, acesso em 9 de maio de 2018. 
FEENBERG, A. O que é a filosofia da tecnologia? In: NEDER, R. (Org.). Andrew Feenberg: racionalização democrática, poder e tecnologia. Brasília: Observatório do Movimento pela Tecnologia Social na América Latina/Centro de Desenvolvimento Sustentável - CDS. Ciclo de Conferências Andrew Feenberg. _ série Cadernos PRIMEIRA VERSÃO: CCTS - Construção Crítica da Tecnologia \& Sustentabilidade. Vol. 1, $\mathrm{n}^{\circ}$. 3. 2010. In: https://www.sfu. ca/ andrewf/coletanea.pdf. acesso em 20 de abril de 2018.

FIGUEIREDO, V. Produção social da tecnologia. São Paulo: E.P.U., 1989.

FONSECA, C.; MEIRELLES, F. \& DINIZ, E. Tecnologia bancária no Brasil: Uma história de conquistas, uma visão de futuro. São Paulo: FGV, 2010.

GIDDENS, A. As consequências da modernidade. São Paulo: Unesp, 1991.

GRÜN, R. Taylorismo e fordismo no trabalho bancário: agentes e cenários. Revista Brasileira de Ciências Sociais. São Paulo, Vol. 1, n. 2, pp. 13-27, 1986.

IANONI, M. Ciência Política e Sistema Financeiro no Brasil: o artigo 192 da Constituição Federal. Florianópolis: Política \& Sociedade. Vol. 9, ñ. 17, pp. 173-204, 2010.

JINKINGS, N. O mister de fazer dinheiro. São Paulo: Boitempo, 1995.

. Trabalho e resistência na "fonte misteriosa": Os bancários no mundo da eletrônica e do dinheiro. Campinas: Editora da Unicamp; São Paulo: Imprensa Oficial do Estado, 2002.

LA GARZA, E. Trabajo no clásico, organización y acción colectiva. Cidade do México: Plaza e Valdés, 2011.

LATOUR, B. Ciência em Ação. São Paulo: Unesp; 2011.

MACHADO, A.; AMORIM, M. Transformações nas relações de trabalho nos bancos: uma trajetória de precarização (1980-2010). Maringá: Acta Scientiarum. Human and Social Sciences. Vol. 34, nº. 2, pp. 179-191, Jul-Dez, 2012.

MINELLA, A. Banqueiros - Organização e poder político no Brasil. Rio de Janeiro: Espaço e Tempo/ANPOCS, 1988.

NETZ, S. Novas tecnologias da informação: Suas influências no trabalho bancário. Anais do XII Congresso Brasileiro de Sociologia, GT 19 - Sociedade de Informação, 2005.

OLIVEIRA, R. G. de. Terceirização e ação sindical no trabalho bancário: dilemas entre o discurso e a prática. 2014. Tese (Doutorado em Sociologia e Antropologia). Programa de Pós Graduação em Sociologia e Antropologia, Universidade Federal do Rio de Janeiro, Rio de Janeiro. 
SANCHES, A. T. Dimensões da difusão tecnológica no setor bancário e a nova divisão do trabalho. 2012. In: https://28deagosto.webnode. $\mathrm{com} /$ news/dimensões $\% 20 \mathrm{da} \% 20$ difusão\%20tecnologica $\% 20$ no $\% 20$ setor $\% 20$ bancario $\% 20 \mathrm{e} \% 20 \mathrm{a} \% 20$ nova $\% 20$ divisão $\% 20$ do\%20trabalho/, acesso em 31 de março de 2018.

.Terceirização e terceirizados no setor bancário: relações de emprego, condições de trabalho e ação sindical. 2006. Dissertação (Mestrado em Ciências Sociais) - Programa de Estudos Pós Graduados em Ciências Sociais, Pontifícia Universidade Católica de São Paulo, São Paulo.

.Trabalho bancário: Inovações tecnológicas, intensificação de controle e gestão por resultados. São Paulo: Annablume, 2017.

SEGNINI, L. Mulheres no trabalho bancário. São Paulo: Edusp, 1998.

SENNET, R. A corrosão do caráter. Rio de Janeiro: Record, 2004.

SOARES, J. L. Radiografia da Mobilização Bancária. 2013. Tese (Doutorado em Sociologia e Antropologia). Programa de Pós-Graduação em Sociologia e Antropologia. Universidade Federal do Rio de Janeiro, Rio de Janeiro.

WINNER, L. Do artifacts have politics? In: WINNER, L. The whale and the reactor - a search for limits in an age of high technology. Chicago: The University of Chicago Press, pp. 19-39. 1986. In: http://www. necso.ufrj.br/Trads/Artefatos $\% 20$ tem $\% 20$ Politica.htm, acesso em 22 de abril de 2018. 